\title{
Impact of high resolution land surface initialization in Indian summer monsoon simulation using a regional climate model
}

\author{
C K Unnikrishnan ${ }^{1, *}$, M Rajeevan ${ }^{2}$ and S Vijaya Bhaskara RaO ${ }^{3}$ \\ ${ }^{1}$ National Centre for Medium Range Weather Forecasting, ESSO MoES, Noida 62, India. \\ ${ }^{2}$ Indian Institute of Tropical Meteorology, Dr. Homi Bhabha Road, Pashan, Pune 411 008, India. \\ ${ }^{3}$ Sri Venkateswara University, Tirupati 517 502, India. \\ ${ }^{*}$ Corresponding author.e-mail: unnikrishnack@gmail.com
}

The direct impact of high resolution land surface initialization on the forecast bias in a regional climate model in recent years over Indian summer monsoon region is investigated. Two sets of regional climate model simulations are performed, one with a coarse resolution land surface initial conditions and second one used a high resolution land surface data for initial condition. The results show that all monsoon years respond differently to the high resolution land surface initialization. The drought monsoon year 2009 and extended break periods were more sensitive to the high resolution land surface initialization. These results suggest that the drought monsoon year predictions can be improved with high resolution land surface initialization. Result also shows that there are differences in the response to the land surface initialization within the monsoon season. Case studies of heat wave and a monsoon depression simulation show that, the model biases were also improved with high resolution land surface initialization. These results show the need for a better land surface initialization strategy in high resolution regional models for monsoon forecasting.

\section{Introduction}

It was demonstrated that the dynamical prediction of the atmosphere is sensitive to the initial land surface conditions (Walker and Rowntree 1977; Fennessy and Shukla 1999). The land surface initialization in a model could impact the forecast skill through slowly varying soil moisture memory and by the surface evapo-transpiration coupling. Most of the previous land surface initialization experiments are performed using low resolution atmospheric general circulation models (Koster and Suarez 2003; Koster et al. 2010). However, regional climate models are available with high resolution and with better representation of regional land surface. This provides a better opportunity to investigate the direct impact of a reliable land surface initialization using a regional climate model.

The seasonal and subseasonal prediction depends on the boundary forcing from sea surface temperature (SST), soil moisture, snow cover and depth, etc. The role of SST in the predictability was demonstrated by earlier studies (Charney and Shukla 1981; Shukla 1981). But the impact of land surface and soil moisture in seasonal and subseasonal prediction in regional climate model is a challenge due to limited and sparse land surface data. The land surface data can impact the simulation using dynamical models in two ways, as the initial conditions for model integration (Fennessy and Shukla 1999; Koster et al. 2010) and slowly varying soil moisture memory as boundary forcing

Keywords. Land surface initialization; soil moisture; monsoon; regional model; drought. 
(Douville 2002). It was shown that land surface initialization improves dynamical prediction (Koster et al. 2010, 2011, Hurk et al. 2012). Walker and Rowntree (1977) showed that the soil moisture can influence the model forecast up to $2-3$ weeks. The outstanding issue over the monsoon region is the lack of reliable observations or analysis data for the initialization of land surface in a high resolution dynamical model. Koster et al. (2010) examined the degree to which realistic land surface initialization contributes to the skill of subseasonal forecasts in the Global Land-Atmosphere Coupling Experiment (GLACE-2). They found that for precipitation forecasts, the contribution of a better land surface initialization to the forecast skill is limited; however, there are some locations where the impact is significant. Guo et al. (2011) showed that realistic land surface initialization can improve the atmospheric predictability significantly out to few months during the summer season. Recently, Paolino et al. (2012) performed a series of forecast experiments for two seasons to examine the impact of specifying a realistic land surface initial state in the Community Climate System Model (CCSM). However, they could not find a major improvement in the forecast skill of precipitation over land region. Case et al. (2008) illustrated the importance of land surface initializing using high resolution land data assimilation system (HRLDAS) in the Weather Research and Forecasting (WRF) model. Their result showed that better land surface initial conditions led to an improvement in daily weather simulations especially improve timing and evolution of local sea breeze circulation. Ferranti et al. (1999) studied the influence of the land surface forcing on intra-seasonal monsoon activity. They suggested that the surface conditions also play a role in the inter-annual predictability of the monsoon.

There are studies on the influence of land surface on Indian summer monsoon using the dynamical models. Previous land coupling study of Koster et al. (2011) showed a significant land-atmosphere coupling over the central and northwest India during the summer season. The recent study of Unnikrishnan et al. (2015) showed the regional differences in the land surface coupling over the Indian monsoon region. They have also showed that the large scale rain is more coupled to the land surface than the convective rain over the monsoon region. Saha et al. (2011) studied on the land-atmosphere interaction on the monsoon onset and its impact on intraseasonal oscillation. They proposed that the land-atmosphere interaction during the monsoon onset can impact the first episode of the intraseasonal oscillation over the Indian subcontinent. Saha et al. (2012) examined the sensitivity of soil moisture on the active and break monsoon spells and they also showed that the soil moisture feedback process can modulate the internal variability of the Indian summer monsoon. However, the direct impact of the initialization of land surface data over the Indian region during the summer monsoon season is not yet investigated in a regional model. This study examines the impact of high resolution land surface initial condition on the regional climate model forecast during the monsoon season. The impact of high resolution land surface state on the model forecast bias in the interannual and subseasonal periods are investigated. Case studies of synoptic systems and intraseasonal spells during the monsoon season were also analysed to understand the high resolution land surface initialization on these systems. The case studies include a heat wave, intraseasonal active and break periods and a monsoon depression over the monsoon region.

WRF regional climate model is used in this study during 2006-2010 period over the monsoon region. For this purpose, a high resolution land surface dataset, developed by forcing HRLDAS using Tropical Rainfall Measuring Mission (TRMM) rainfall and European Centre for Medium-Range Weather Forecasting (ECMWF) atmospheric parameters were used. The description and validation of the land surface data used for initialization of the regional climate model are given by Unnikrishnan et al. (2013). Section 2 discusses the model and methodology used; section 3 discusses about the important results and section 4 summarizes and concludes the results.

\section{Model and methodology}

A regional dynamical model (RCM) benefits for its higher resolution and further solves better orographic, land surface representations and they are also equipped with many interactive physical parameterizations. This provides an advantage for regional climate models over global models especially in the regional climate studies. Therefore, RCMs are more preferred for the studies on landatmosphere coupling. The WRF model version 3.3 was used as a regional climate model and implemented with Noah land surface scheme (Chen and Dudhia 2001) with four soil layers with the thicknesses of 10, 30, 60 and $100 \mathrm{~cm}$ from the top to down. The model was implemented with a horizontal resolution of $45 \mathrm{~km}$ and 28 vertical levels. The model was forced using Final (FNL) analysis (from NCEP) with $1^{\circ}$ horizontal resolution as boundary conditions. The lateral and lower boundary conditions from FNL were updated in every 6 hrs. The lateral boundary includes the following atmospheric variables: horizontal wind, temperature, 
geo-potential height, water vapour and surface pressure and the lower boundary is the sea surface temperature (SST). For the convective parameterization, Betts Miller Janjic scheme (Betts 1986; Betts and Miller 1986; Janjic 2000) was used. The microphysics scheme of Lin et al. (1983) was also used. MoninObukhov similarity scheme (Monin and Obukhov 1954) was used for the surface layer parameterization. The Yonsei University parameterization scheme was used for the boundary layer (Hong and Dudhia 2003). We used model configuration and parameterizations similar to that used in Indian summer monsoon simulation by Bhate et al. (2012).

To study the impact of high resolution land surface initialization, two separate experiments were performed. In the first case, land surface was initialized with land surface dataset developed using the HRLDAS model (EXP1). The HRLDAS soil moisture and soil temperature at all soil levels are used for initializing the model values in EXP1. In the second case, land surface was initialized using the coarse resolution FNL data (EXP2). The HRLDAS data (Unnikrishnan et al. 2013) have better spatial $\left(0.5^{\circ}\right)$ and temporal $(1 \mathrm{hr})$ resolution compared to FNL data which have a $1^{\circ}$ horizontal resolution in 6 hourly intervals. HRLDAS data has an advantage of the use of observed rainfall forcing (hourly) and vegetation fraction (weekly). The TRMM 3B42 daily rainfall (Hauffman et al. 2007 ) is used to estimate the rainfall bias in the model. The model is initialized on every 1st June at 00 UTC during the period 2006-2010 and integrated up to 1st October. The National Centers for Environmental Prediction (NCEP) FNL data is available at http://rda.ucar.edu/datasets/ds083. 2/. However, for the case studies, the experiment (EXP1) (with HRLDAS initialization) is carried out by re-initializing the soil moisture and soil temperature just one day before the starting of the events.

The bias in rainfall is calculated for the subseasonal scale simulations. The differences between the experiments are compared by calculating bias and differences in bias (difference of bias in EXP1 and EXP2). Subseasonal rainfall simulations for the period, July-August are compared with the TRMM observed rainfall of the corresponding period. A few more case studies are also considered to examine the impact of initialization of land surface processes. The case studies include extended break monsoon spell and an active monsoon spell in the year 2009, one monsoon depression case and one heat wave case during the monsoon season. Simulated rainfall pattern is compared with TRMM observations in active-break monsoon periods and the case of monsoon depression. In the heat wave condition, model simulated surface air temperatures at $2 \mathrm{~m}$ and sensible heat flux are also compared with the Modern Era RetrospectiveAnalysis for Research and Analysis (MERRA) (Rienecker et al. 2011).

\section{Results and discussions}

\subsection{Subseasonal simulation of monsoon rainfall}

It is already shown that the WRF regional climate model can simulate the mean rainfall and wind patterns during the monsoon season reasonably well (Bhate et al. 2012). However, the model shows a wet bias $\left(4.3 \mathrm{~mm}\right.$ day $\left.^{-1}\right)$ over central India on the seasonal time scale. The bias in the seasonal rainfall over central India $\left(75-88^{\circ} \mathrm{E}\right.$ and $\left.18-27^{\circ} \mathrm{N}\right)$ is calculated using the model results and the TRMM 3B42 derived rainfall during the period 2006-2010. Table 1 shows the seasonal rainfall bias (model simulated-observed) averaged over central India during June-September. Better land surface initialization (EXP1) reduced the rainfall bias over central India region up to $1.5 \mathrm{~mm}$ day $^{-1}$ during the monsoon season. The average seasonal rainfall shows an improvement in bias $0.6 \mathrm{~mm}$ day $^{-1}$ during 2006-2010. The bias results suggest that land surface initialization improved mean seasonal simulation over central India. The $t$-test shows that the

Table 1. Seasonal (June-September) monsoon rainfall bias (model-observations) in $\mathrm{mm} d a y^{-1}$ over central India during 2006 to 2010.

\begin{tabular}{|c|c|c|}
\hline \multirow[b]{2}{*}{ Year } & \multicolumn{2}{|c|}{$\begin{array}{c}\text { Rainfall bias (mm day }{ }^{-1} \text { ) with observations } \\
\text { during JJAS }\end{array}$} \\
\hline & $\begin{array}{l}\text { EXP2 } \\
\text { (coarse land surface } \\
\text { data initialization) }\end{array}$ & $\begin{array}{c}\text { EXP1 } \\
\text { (with HRLDAS land surface } \\
\text { data initialization) }\end{array}$ \\
\hline 2006 & 5.4 & 4.1 \\
\hline 2007 & 3.3 & 3.4 \\
\hline 2008 & 4.8 & 4.8 \\
\hline 2009 & 4.5 & 3.0 \\
\hline 2010 & 3.8 & 3.4 \\
\hline
\end{tabular}

Table 2. Correlation coefficient of pentad rainfall between model simulations and observed (TRMM) over central India during June-September period (correlation coefficients above 0.4 are significant at $95 \%$ significance level).

\begin{tabular}{ccc}
\cline { 3 - 3 } Year & $\begin{array}{c}\text { Correlations of model pentad rainfall with observations } \\
\text { (coarse land surface } \\
\text { data initialization) }\end{array}$ & $\begin{array}{c}\text { EXP1 } \\
\text { (with land surface } \\
\text { initialization) }\end{array}$ \\
\hline 2006 & 0.54 & 0.56 \\
2007 & 0.53 & 0.48 \\
2008 & 0.36 & 0.46 \\
2009 & 0.68 & 0.69 \\
2010 & 0.47 & 0.49 \\
\hline
\end{tabular}



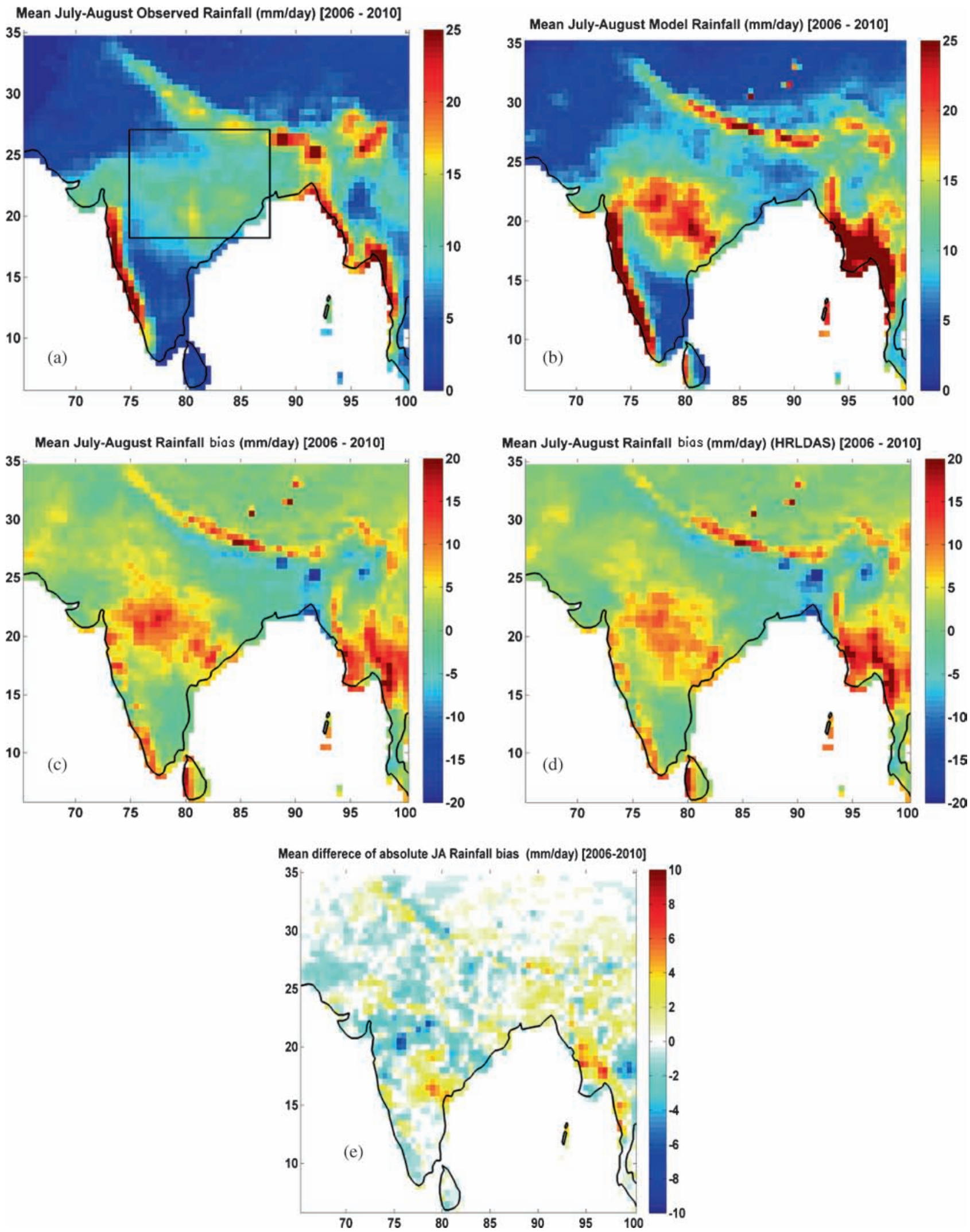

Figure 1. Comparison of simulation of subseasonal rainfall $\left(\mathrm{mm} \mathrm{day}^{-1}\right)$ with and without land-surface initialization. (a) July-August TRMM observed rainfall $\left(\mathrm{mm} \mathrm{day}^{-1}\right.$ ) during 2006-2010, (b) model rainfall ( $\mathrm{mm} \mathrm{day}^{-1}$ ), $(\mathbf{c})$ same period $^{-}$ rainfall model bias (EXP2), (d) model bias in rainfall for the same period with HRLDAS (EXP1) and (e) absolute difference between experiment bias (bias of EXP1-bias of EXP2). 
difference between EXP1 and EXP2 are significant at 0.07 levels.

Correlations between the model simulations and observations of pentad rainfall (5-day averages) during the monsoon period were also calculated. The results are shown in table 2 . It is seen that the correlations are improved with the land surface initializations for each year except in 2007. However, improvement in biases and skills (correlations) are not appreciable except for 2009. It is interesting to note that the land surface impact is observed to be more in a drought year like 2009 (in terms of reduction of bias). This suggests that the impact of land surface processes could be more effective in more arid conditions. These results suggest that slowly varying soil moisture memory over the monsoon region may be useful for the seasonal prediction during the drought years. It is observed that, by overall, the seasonal rainfall simulation and skill of the model over central India show an improvement with HRLDAS initialization (EXP1). The results show an appreciable improvement in the reduction of model bias during the drought year like 2009 . The impact of the land surface initialization using the newly developed data is investigated for JulyAugust period. The mean July-August bias is calculated for the two experiments (EXP1 and EXP2) for the period, 2006-2010 separately. Further, the absolute differences between these bias are also calculated (i.e., bias of EXP1 - bias of EXP2).

The model overestimates rainfall over central Indian region. Figure 1 shows the comparison of bias in subseasonal rainfall. The mean TRMM observed rainfall $\left(\mathrm{mm} \mathrm{day}^{-1}\right)$ is shown in figure $1(\mathrm{a})$. The model rainfall is shown in figure $1(\mathrm{~b})$ and the model bias (model rainfall - observed rainfall) of EXP1 is shown in figure $1(\mathrm{~d})$. The high bias during the period, July and August is mostly seen over the Western Ghats and the central Indian regions. Northeast region shows a negative (dry) bias compared to observations. The model bias of EXP2 is shown in figure 1(c), this bias is also similar to EXP1. However, there are differences in the rainfall pattern, there are regional differences in the magnitude of rainfall bias over the central India and the west coast. The differences between the bias between EXP1 and EXP2 (bias of EXP1 - bias of EXP2) are shown in figure 1(e). This difference in bias shows a mixed response, most areas in central India shows positive result (reduction in bias (negative values) in EXP1). However, there are small patches (Andhra Pradesh, northeast regions) which show a small increase of bias in EXP1. Over all, the results show that the rainfall bias during July and August over many places of central India are reduced compared to EXP2. $T$-test is conducted for EXP1 and EXP2 forecasts in this case, results show that the differences are significant at 0.1 levels. These results are similar to the land surface initialization results of Koster et al. (2010) over North America.

\subsection{Case studies}

Is the land surface initialization improves simulation of different weather systems observed within the monsoon season? This section examines this aspect with analysis of few case studies. The impact of land surface initialization experiments are evaluated for the case of break and active monsoon periods, a monsoon depression and a heat wave during the monsoon season.

\subsubsection{Active and break monsoon spells}

The active and break periods during the monsoon season are identified using daily rainfall over central India using the criteria proposed by Rajeevan et al. (2010). The active period is identified as the period in which the standardized rainfall averaged over central India is more than +1.0 . The break period is identified in similar way but when the standardized rainfall is less than -1.0 . In the year 2009, the active period is identified as 19-23rd July and the break period is in between 29th July and 10th August. Figure 2 shows the rainfall time series over central India during the active and break periods during the 2009 monsoon season. The results show that the model simulations are improved after the HRLDAS initialization (EXP1). It is observed that extended break period is more positively responding with the better land surface initialization. It is seen that the bias during extended break period during 2009 is reduced by $\sim 10 \mathrm{~mm}$ day $^{-1}$ with HRLDAS initialization. For a detailed analysis, the spatial rainfall features are also compared.

The observed rainfall shows less rainfall over central India and many locations over the Indian subcontinent during this extended break period and is shown in figure 3(a). The bias during this period is shown in figure 3(d) EXP1 and 3(c) EXP2 respectively. Both EXP1 and EXP2 show that the model rains more over the central India region. The difference between the bias of EXP1 and EXP2 shows negative over most of the region during the break condition (figure 3e). T-test is performed for EXP1 and EXP2 for break case, the results show that the differences are significant at 0.01 levels. This suggests that model initialized with HRLDAS is performing better in the simulation of rainfall during the break monsoon period (EXP1).

Similarly, the active monsoon rainfall simulations are compared with observations (figure 4). The TRMM observations show heavy rainfall over the central India Odissa and the Western Ghats 


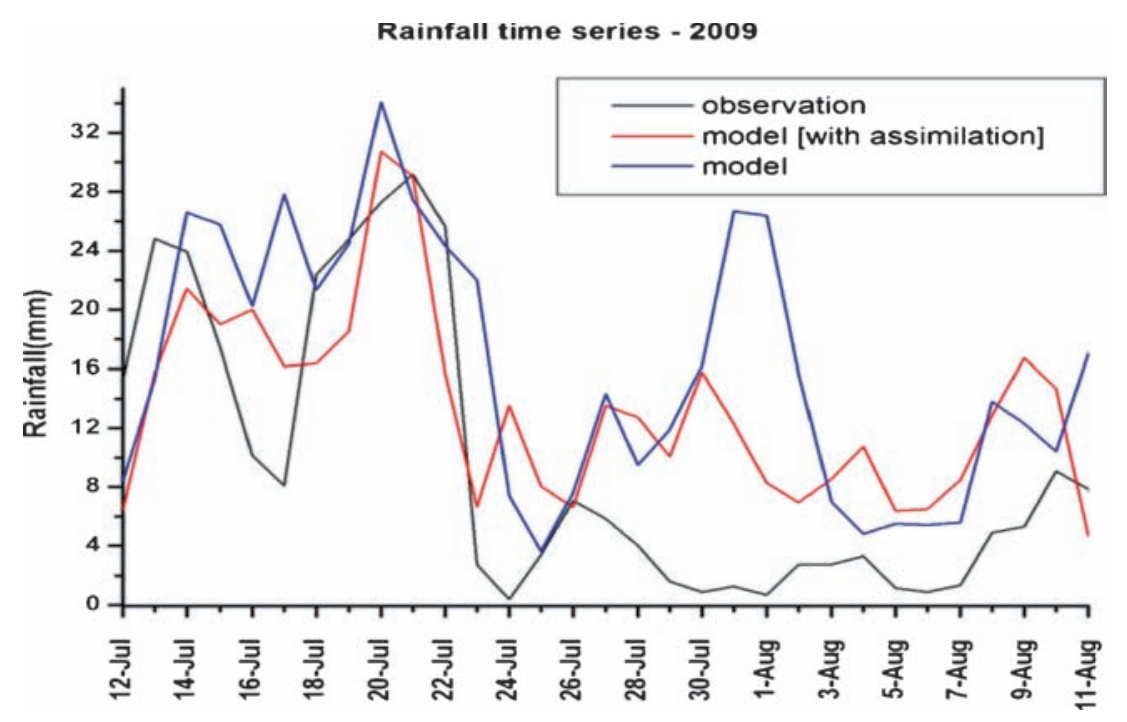

Figure 2. Observed and model-simulated daily rainfall $\left(\mathrm{mm} \mathrm{day}^{-1}\right)$ time series over central India during an active and break spell during the 2009 monsoon season (EXP1: red line, EXP2: blue line) and observation: black line).

(figure 4a). However, the rainfall over northeast region is less compared to the break period. Figure 4(b) shows the model rainfall during the same period. The rainfall biases are calculated for the two experiments EXP1 and EXP2 (figure 4d and c). The difference between the bias of the EXP1 and EXP2 shows a mixed response (figure 4e), there are positive and negative values over the domain suggesting that the active period is less influenced by the HRLDAS initialization. This may be due to the fact that during active monsoon periods, rainfall activity is mainly due to the weather systems originating over the Bay of Bengal. In that case, the land surface impact is less or masked. This shows that the positive impact of land surface initialization is high during the dry periods; during dry period, the slowly varying soil moisture anomalies improve the model forecast. However, the rainfall in the wet period is mainly oceanic in origin and the role of land surface is comparatively less. This explains the relatively less influence of land surface on the wet spells. $T$-test is performed for the EXP1 and EXP2 in this experiment, the results show that the differences in experiments are significant at 0.01 level.

\subsubsection{Heat wave}

Heat wave condition in June 2009 over the north Indian region is considered to evaluate the impact on land surface data initialization. A heat wave was observed between 11th June and 26th June, over most parts over the central and north India with abnormal high temperatures. Unnikrishnan et al. (2013) showed the land surface features and anomalies of this extended heat wave event. The spatial pattern of $2 \mathrm{~m}$ air temperature and sensible heat flux are compared with the MERRA reanalysis. Figure 5 shows the $2 \mathrm{~m}$ temperature during the 2009 heat wave in June: (a) reanalysis, (b) model, (c) bias in EXP2, (d) bias in EXP1, and (e) difference in bias between EXP1 and EXP2, respectively. Figure 5(a) shows that most parts of north India and central India are marked with high temperatures exceeding $40^{\circ} \mathrm{C}$. However, the EXP1 and EXP2 show a negative bias, suggesting that the model underestimated high temperatures during the heat wave episode. The difference between biases (EXP1 - EXP2) shows negative over central India region suggesting that HRLDAS initialization improved the model temperature simulation during this heat wave case.

The heat waves are generally marked with high surface sensible heat flux. The model simulated sensible heat fluxes are compared with observations. For observations, the MERRA analysis data were used. Figure 6 shows the surface sensible heat flux during the 2009 heat wave in June: (a) reanalysis, (b) model, (c) bias in EXP2, (d) bias in EXP1, and (d) differences in bias (EXP1 - EXP2), respectively. The reanalysis shows more than $100 \mathrm{Wm}^{-2}$ sensible heat flux over many parts of north India (figure 6a). The model sensible heat bias is negative over central India and many parts of north India as a result of cold bias in temperature and wet bias in rainfall in the regional climate model. The difference between the bias in EXP1 and EXP2 shows negative over most of the places which shows that the HRLDAS initialization improved the sensible heat flux by $25-50 \mathrm{Wm}^{-2}$ and $2-6^{\circ} \mathrm{C}$ improvement in $2 \mathrm{~m}$ temperature over many places over central India. Both temperature $(2 \mathrm{~m})$ and soil moisture biases are reduced with the initialization of HRLDAS over central India and most of the region 

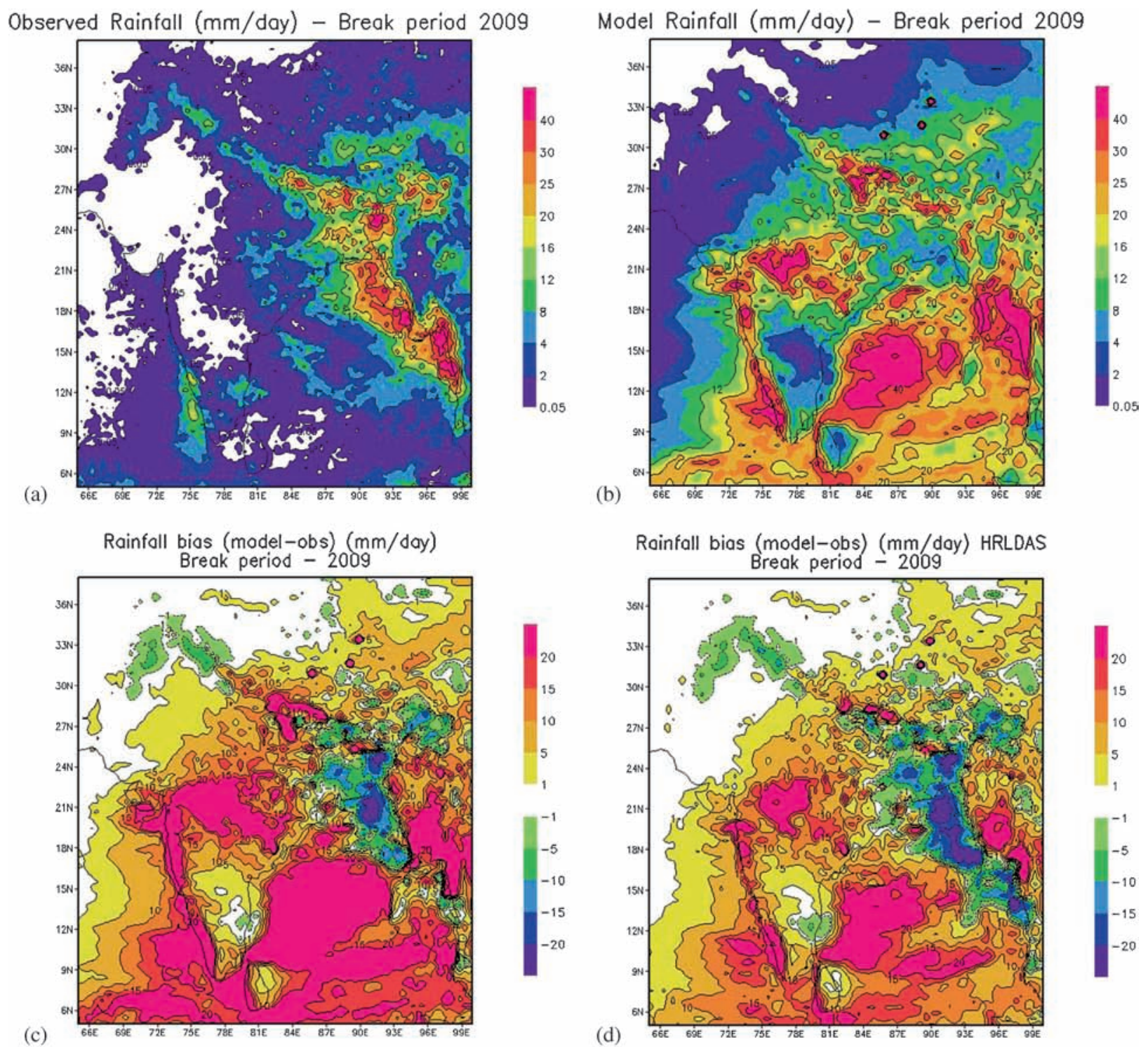

b)

Roinfall bias (model-obs) (mm/doy) HRLDAS
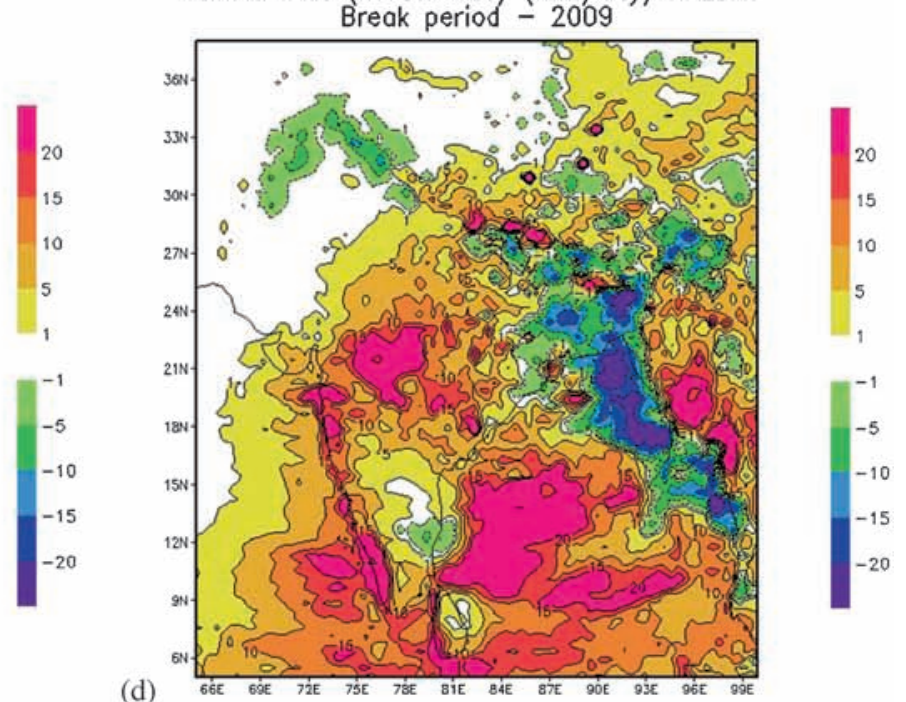

Mean difference of absolute Roinfoll bios ( $\mathrm{mm} /$ doy) Break period 2009

(e)

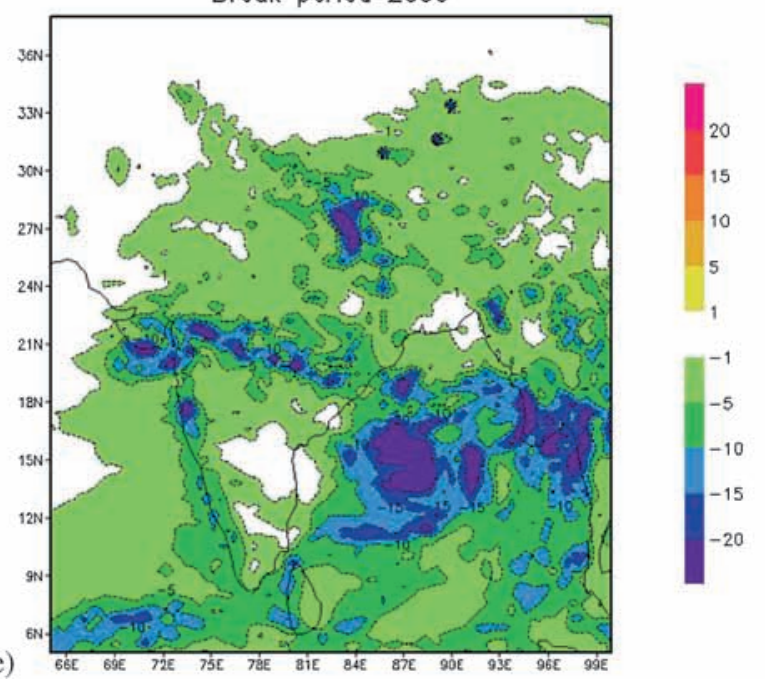

Figure 3. (a) TRMM observed rainfall $\left(\mathrm{mm} \mathrm{day}^{-1}\right)$ during the break monsoon period in 2009, (b) model rainfall (EXP1), (c) same period rainfall model bias (EXP2), (d) same period rainfall model bias with HRLDAS soil moisture initialization (EXP1) and (e) absolute difference between experiment bias (bias of EXP1 - bias of EXP2). 
Observed Rainfall (mm/day) Active period 2009

(a)
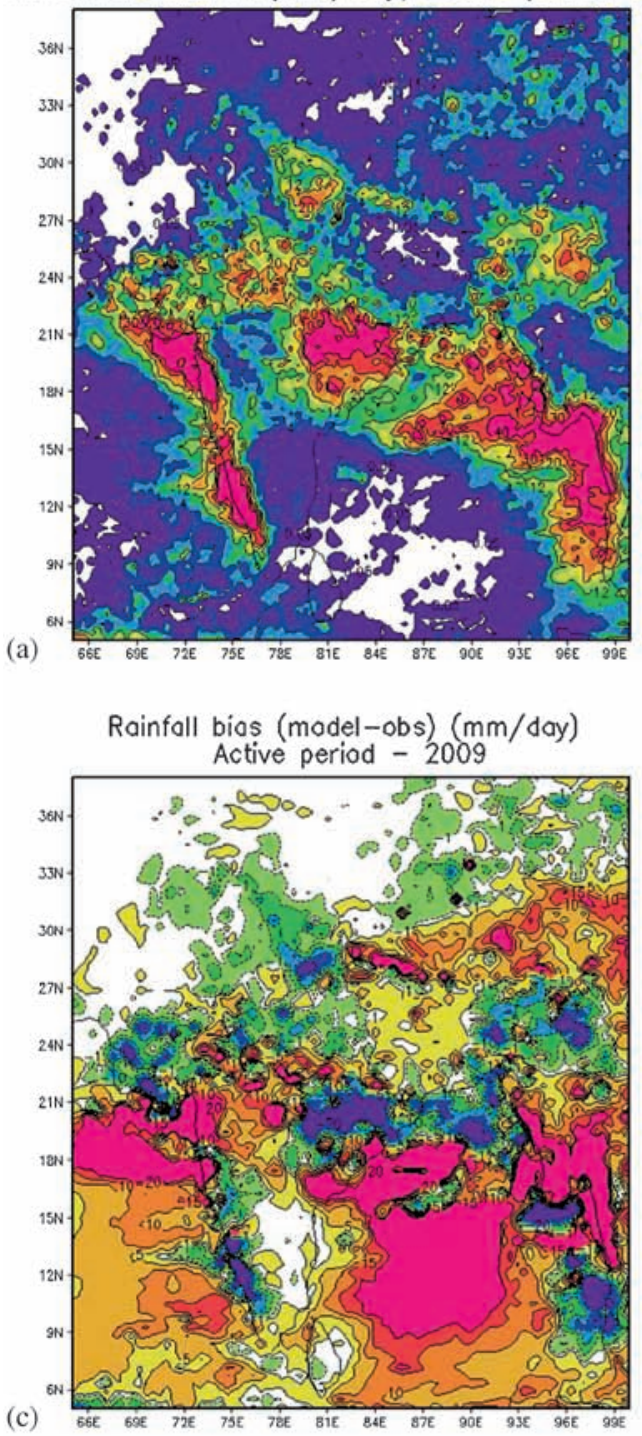

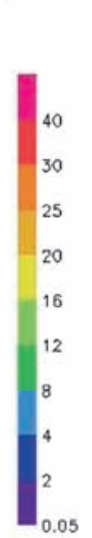

Model Roinfall (mm/day) Active period 2009

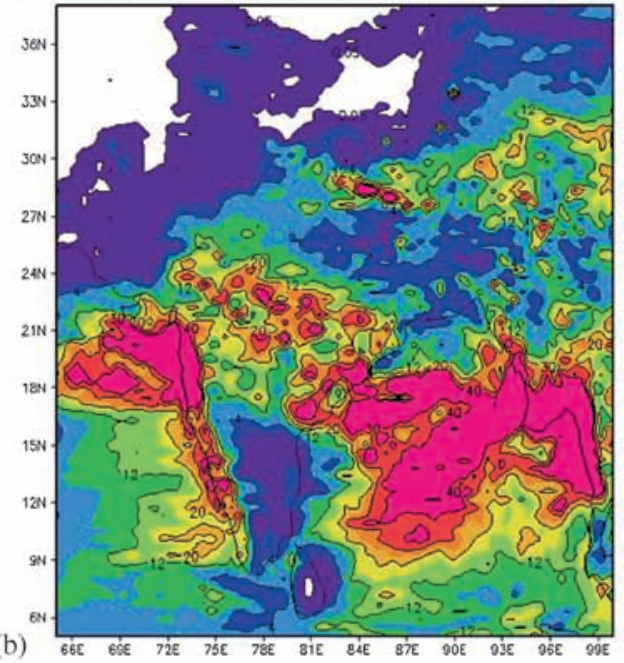

Roinfall bias (model-obs) (mm/doy) HRLDAS

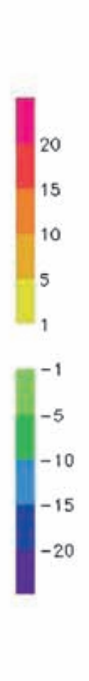

Active period - 2009

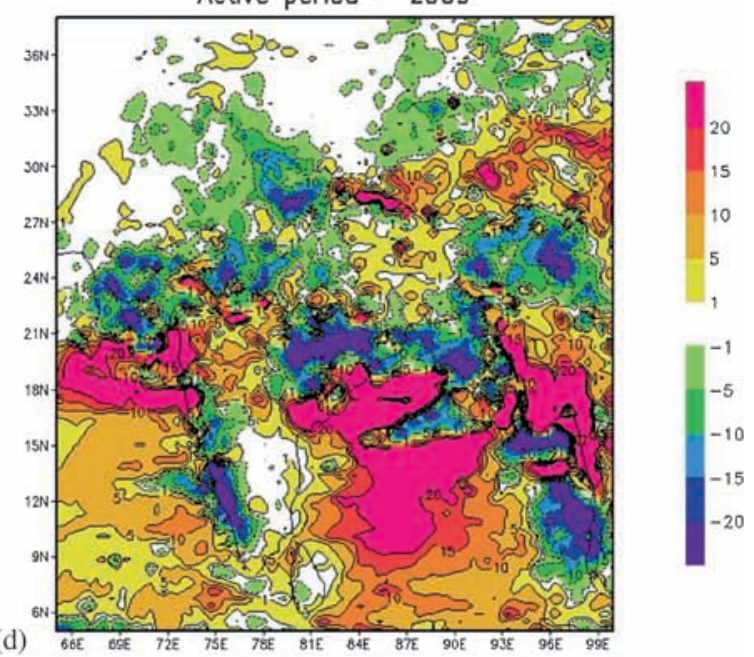

Mean difference of absolute Rainfoll bios (mm/day)

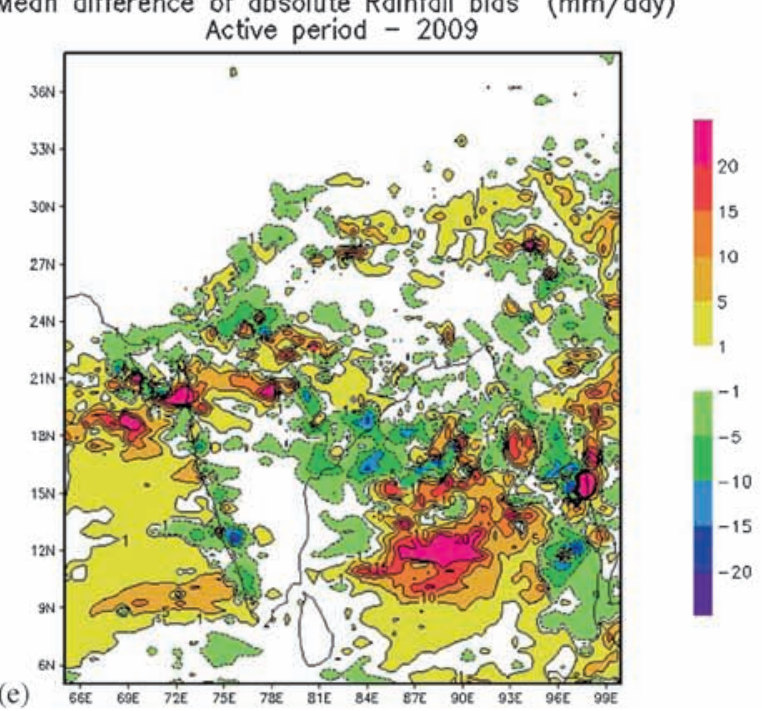

Figure 4. (a) TRMM observed rainfall $\left(\mathrm{mm} \mathrm{day}^{-1}\right)$ during the active monsoon period in 2009 , (b) model rainfall (EXP1), (c) same period rainfall model bias (EXP2), (d) same period rainfall model bias with HRLDAS soil moisture initialization (EXP1), and (e) absolute difference between experiment bias (bias of EXP1 - bias of EXP2). 

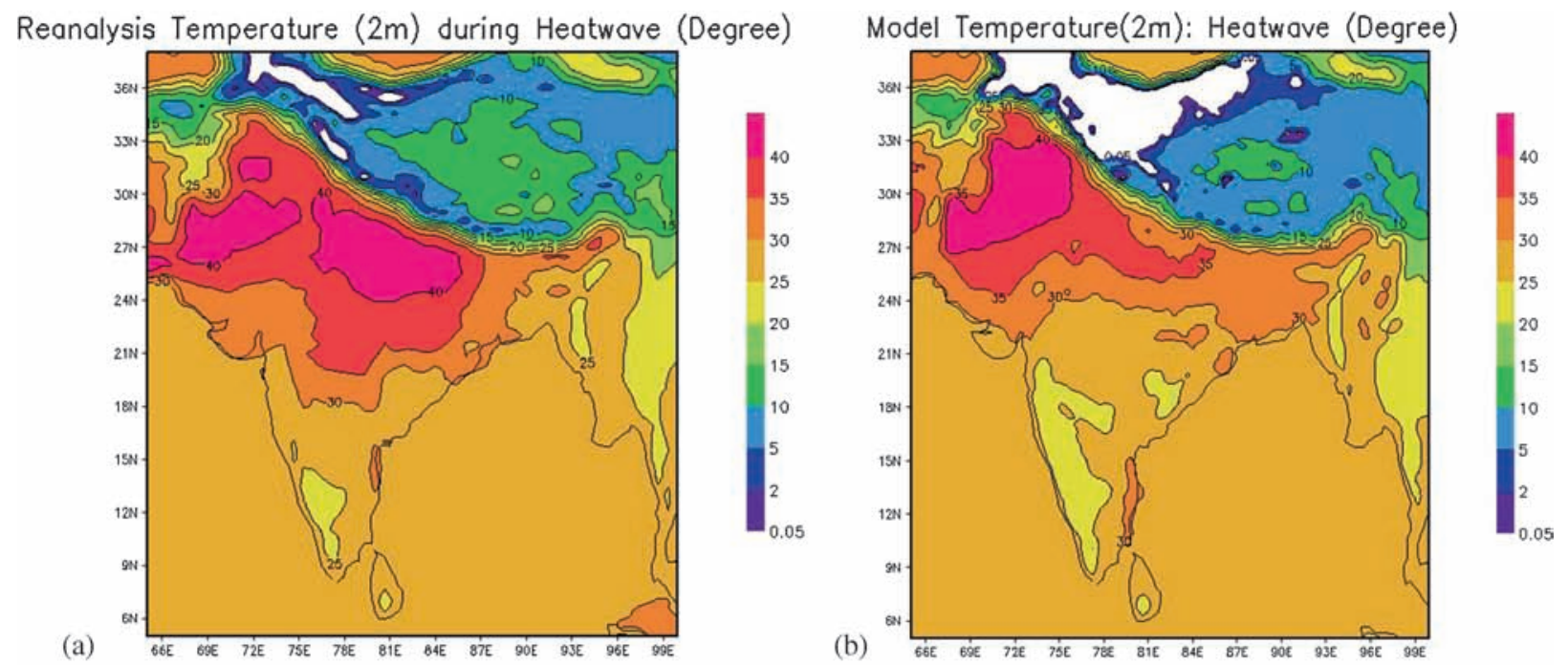

Temperature $\underset{\text { Heat wave }-2009}{2 m}$ bios $($ model-obs) (Degree)

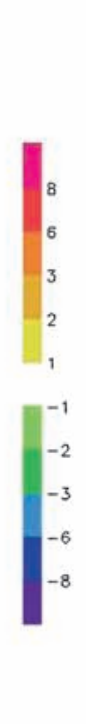

Temperature $(2 \mathrm{~m})$ bios (model-obs)
Heot wove -2009
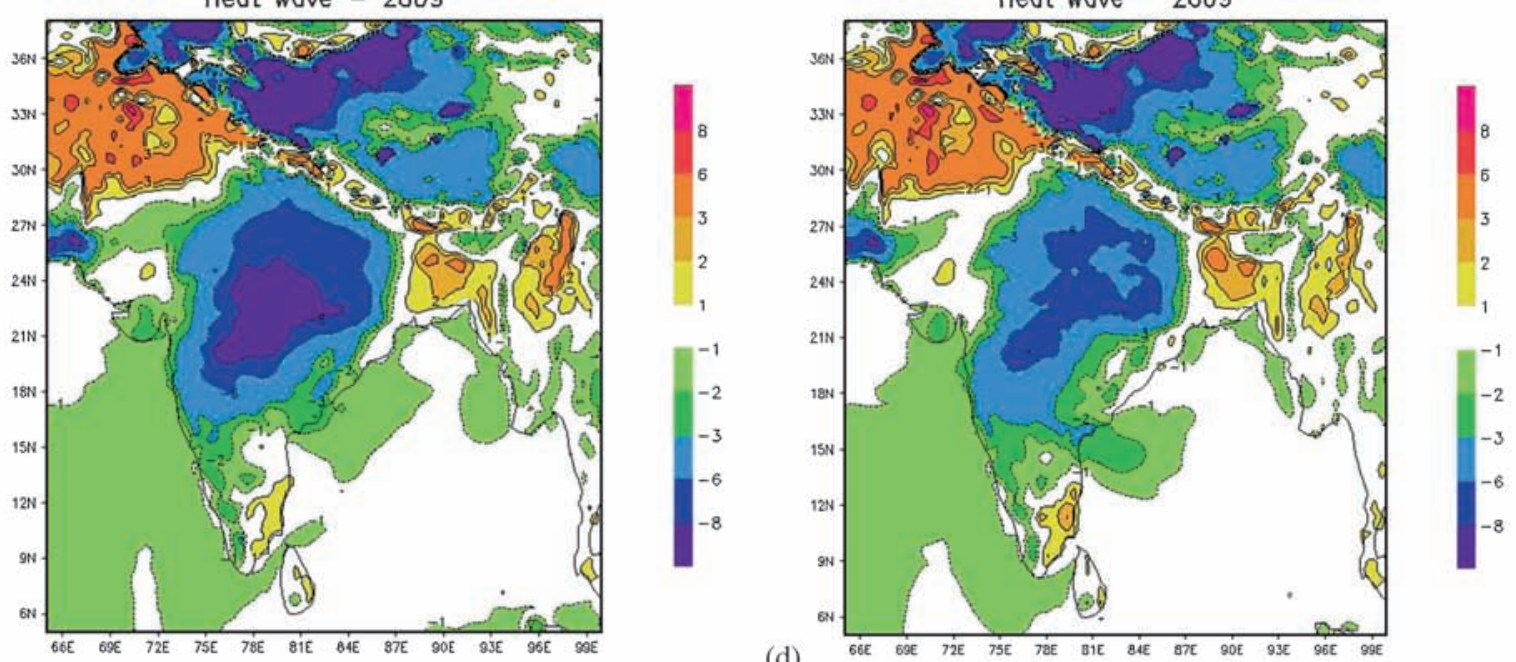

Mean difference between Temperoture $(2 \mathrm{~m})$ obsolute bios (Degree) Heat wave - 2009

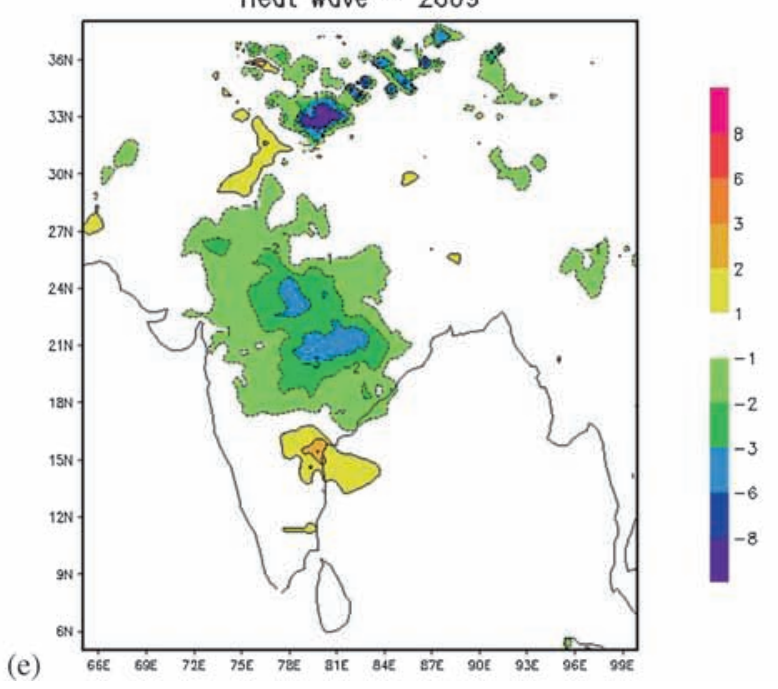

Figure 5. (a) MERRA reanalysis air temperature $(2 \mathrm{~m})\left({ }^{\circ} \mathrm{C}\right)$ during a heat wave case in the 2009 monsoon season, (b) model (EXP1) temperature $\left({ }^{\circ} \mathrm{C}\right)$, (c) temperature model bias in EXP2 for the same period, (d) temperature model bias with HRLDAS soil moisture initialization (EXP1) for the same period and (e) absolute difference between experiment bias (bias of EXP1 - bias of EXP2). 

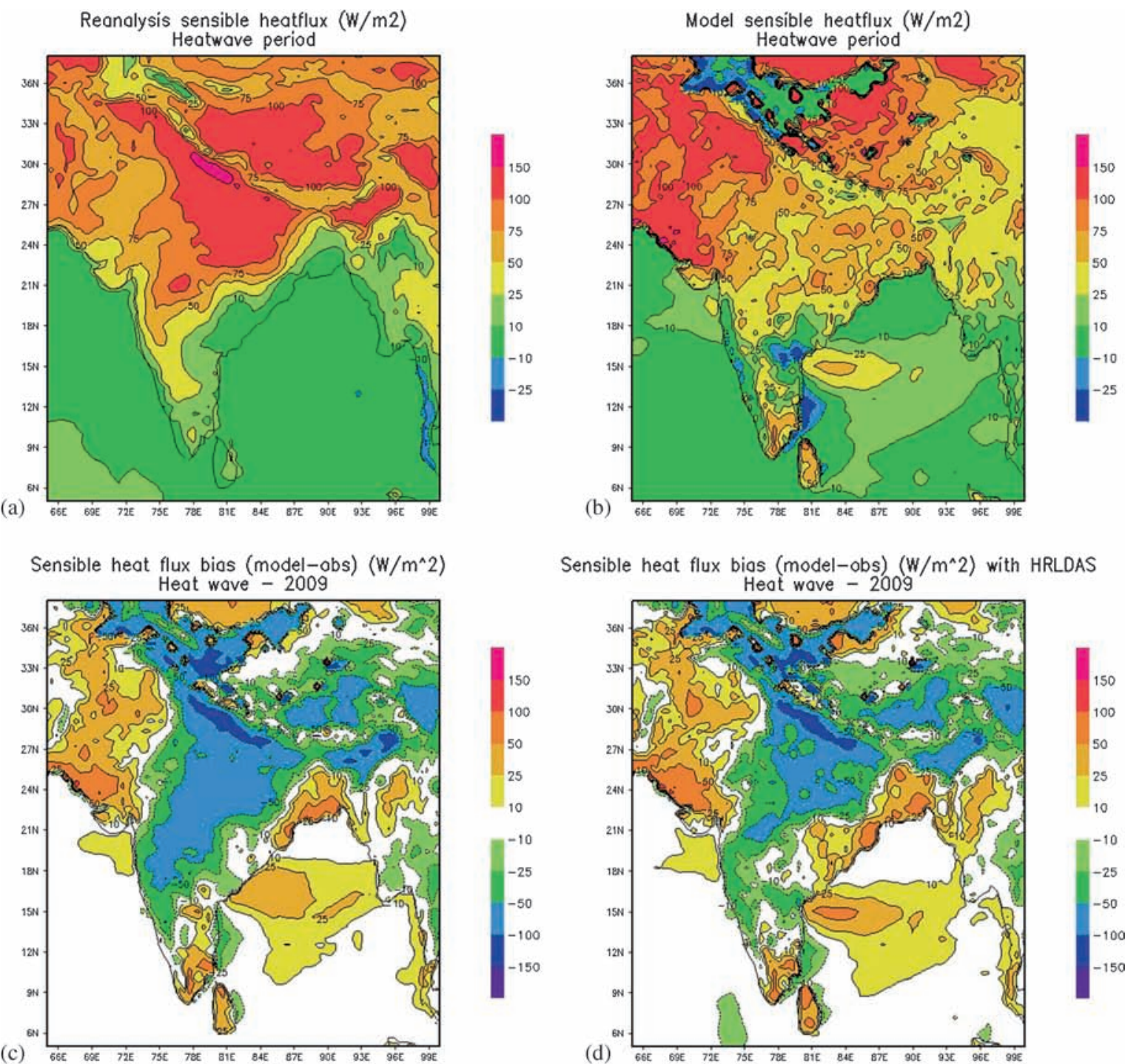

Sensible heat flux bios (model-obs) $\left(W / m^{\wedge} 2\right)$ with HRLDAS
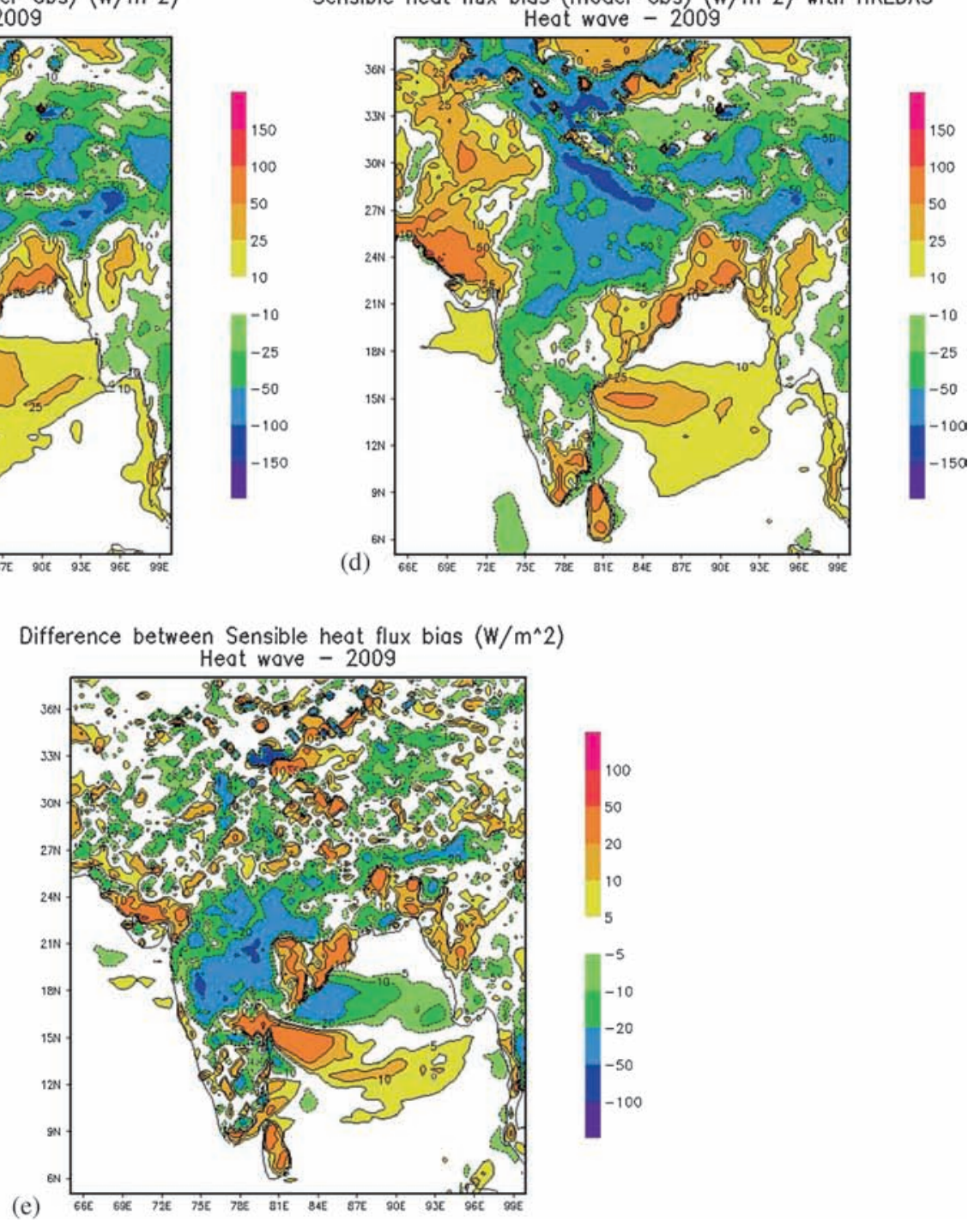

Figure 6. (a) Shows the MERRA reanalysis surface sensible heat flux $\left(\mathrm{Wm}^{-2}\right)$ during heat wave case in 2009 monsoon season, (b) model surface heat flux $\left(\mathrm{Wm}^{-2}\right)$, (c) same period surface sensible heat flux model bias in EXP2, (d) same period surface sensible heat flux model bias in EXP1 (with HRLDAS soil moisture initialization) and (e) absolute difference between the experiment bias (bias of EXP1 - bias of EXP2). 

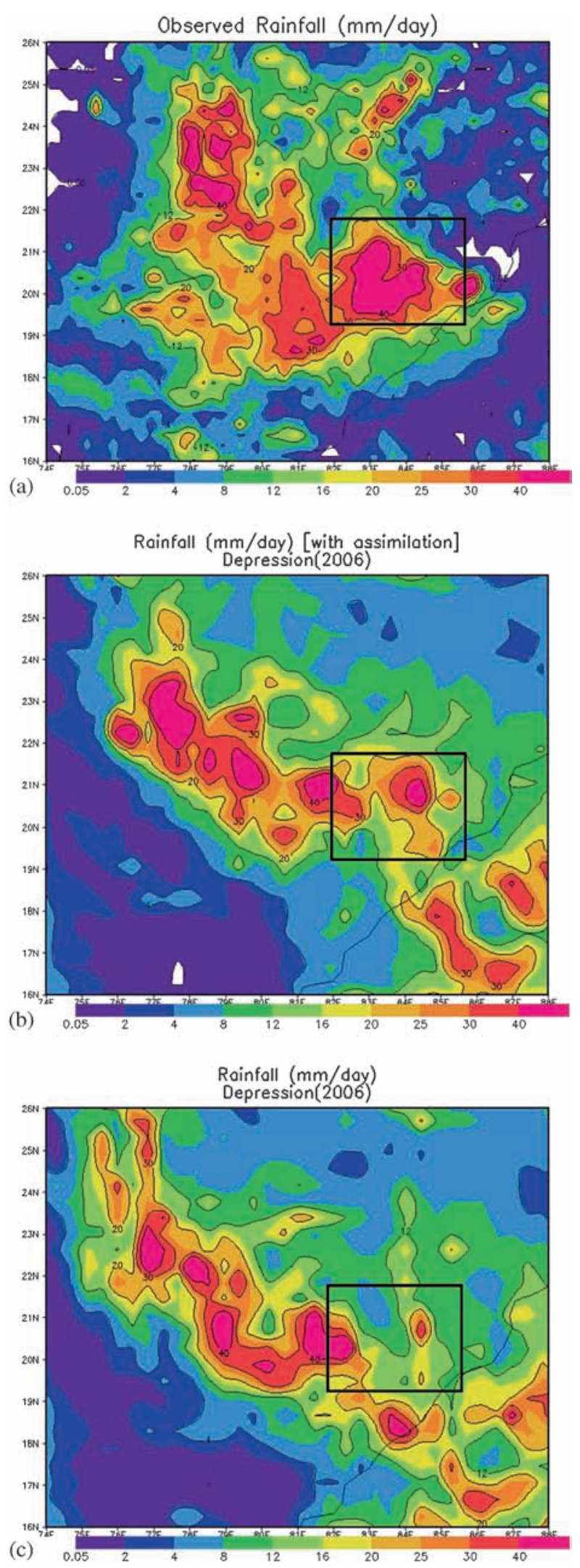

Figure 7 . The accumulated daily mean rainfall $\left(\mathrm{mm} \mathrm{day}^{-1}\right)$ during the passage of a monsoon depression between 29 August and 1 September, 2006: (a) Observed, (b) EXP1 (with HRLDAS initialization) and (c) EXP2. The box marks the heavy rainfall after the land fall of the depression. during the heat wave period. T-test is performed for the heat wave case, the results show that the differences between EXP1 and EXP2 are significant at 0.01 level. Heat wave depends on the atmospheric circulation; however, the land surface can modulate it. Therefore, the improvements in the initial land surface variables alone cannot improve the forecast.

\subsubsection{Monsoon depression}

The impact of HRLDAS initialization in case of a monsoon depression is also investigated. Enhanced rainfall activity due to the passage of a monsoon depression is observed over east-central parts of India between 29th August, 2006 and 1st September, 2006. In this case, the model soil moisture is reinitialized one day before the formation of the depression. The monsoon depression was formed over the Bay of Bengal on 27th August 2006. It moved westwards and crossed the Odisaa coast on 29th August and it further moved to northwest over the land area up to 1st September and weakened subsequently. The accumulated mean rainfall between 29th August and 1st September is compared with the model simulated rainfall.

Figure 7 shows the accumulated daily mean rainfall during the passage of monsoon depression: (a) observed, (b) EXP1, and (c) EXP2. The passage of depression resulted in heavy rainfall over many parts of central India. Model could capture the broad rainfall features, but with a spatial shift in the heavy rainfall zone. It is observed that EXP1 captures the rainfall pattern comparatively better. It is interesting to note that the landfall rainfall is better simulated in EXP1 (marked with box in the figure). This analysis suggests that a better land surface initialization improves the simulation of rainfall activity associated with the monsoon depression.

\section{Summary and discussion}

This paper investigated the direct impact of a better land surface initialization in recent decade using the WRF regional climate model for the seasonal, subseasonal rainfall and a few case studies of (a) active spell, (b) break spell, (c) heat wave, and (d) monsoon depression. Two separate experiments are also performed; one with a realistic land surface initialization using new land surface data developed using the HRLDAS. The second experiment uses the FNL analysis data, a course resolution land surface condition. HRLDAS data is more realistic over the domain due to the observed rainfall and vegetation fraction used as forcing parameters. It also has high temporal and spatial resolution, compared with the FNL analysis. 
The results show that the subseasonal rainfall bias is reduced with a better initial condition using HRLDAS data. The average seasonal bias was reduced by $0.6 \mathrm{~mm}$ day ${ }^{-1}$ during the season and the drought year 2009 shows a better bias improvement $\left(1.5 \mathrm{~mm} \mathrm{day}^{-1}\right)$. This shows the importance of land surface initial conditions on the subseasonal simulation of monsoon rainfall using the WRF regional climate model. The subseasonal rainfall bias in July and August was slightly improved after the HRLDAS assimilation over many places over central India and adjoining areas. This result shows that the impact of the land surface initialization can impact the subseasonal rainfall and better land surface representation in a regional climate model that can improve the subseasonal rainfall forecasts.

Case study of active and break monsoon period in 2009 is carried out to investigate the impact of HRLDAS initialization in the regional climate model. The active monsoon period during the period, 19th-23rd July and the break monsoon period during the period 29th July-10th August are considered for the analysis. The analysis shows that the HRLDAS initialization improves the simulation of rainfall distribution during both active and break monsoon periods. However, it is noted that the impact of land surface data initialization is stronger for the break monsoon period case. The bias during the extended break period was reduced by $10 \mathrm{~mm}$ day $^{-1}$ with the HRLDAS initialization. A slight improvement over central India is only seen during the active period. This shows that the response to land surface data initialization is different for active and break conditions. The results also suggest that land surface data initialization may improve intraseasonal rainfall prediction, especially the break monsoon events. This result also shows that there are differences in the response to land surface initialization within a season by wet and dry spells.

Case studies of a heat wave event and monsoon depression case are also analyzed to verify the importance of land surface initialization. The impact of HRLDAS initialization on a heat wave case (11-26 June, 2009) was compared with the MERRA reanalysis. The HRLDAS land surface initialization shows an improvement of $2^{\circ}-6^{\circ} \mathrm{C}$ in $2 \mathrm{~m}$ air temperature and approximately $25-50 \mathrm{Wm}^{-2}$ improvement in sensible heat flux over many parts of north India. Importance of HRLDAS initialization of a monsoon depression rainfall is also investigated. The case study of monsoon depression over land during 29th August, 2006-1st September, 2006 is considered and accumulated mean rainfall is compared with the HRLDAS initialization experiment. Result shows that the accumulated daily mean rainfall pattern associated with the monsoon depression is improved with the HRLDAS land surface initialization in the model. These results highlight that bias of simulations of synoptic systems within seasonal period is improved with better land surface initialization. The high resolution land surface initialization improves the regional soil moisture anomalies and surface flux in the model. The surface flux can further impact the atmospheric boundary layer stability and model evolution. This improved the regional model forecast. There is a scope to repeat these experiments with an ensemble model simulation for more years which can improve the robustness of these results and it may reduce the uncertainty of these results.

These results show the importance of land surface initialization in high resolution regional models over the monsoon region. This also highlights the need for a better regional land assimilation system over the monsoon region. This may need installation of more in-situ observatories and real time satellite observations.

\section{Acknowledgements}

The authors thank the Director, National Atmospheric Research Laboratory, Gadanki, India for providing support and encouragement to carry out this study. The TRMM rainfall data used in this study were produced with the Giovanni online data system, developed and maintained by the NASA GES DISC. MERRA reanalysis data used in this study have been provided by NASA data server. FNL data is obtained from NCEP server. They also thank the editor and anonymous reviewers for their constructive comments, which helped to improve the manuscript.

\section{References}

Betts A K 1986 A new convective adjustment scheme. Part I. Observational and theoretic basis; Quart. J. Roy. Meteor. Soc. 112 677-691.

Betts A K and Miller M J 1986 A new convective adjustment scheme. Part II: Single column tests using GATE wave, BOMEX, and Arctic air mass data sets; Quart. J. Roy. Meteor. Soc. 112 693-709.

Bhate Jyoti, Unnikrishnan C K and Rajeevan M 2012 Regional climate simulation of the 2009 Indian summer monsoon; Indian J. Radio and Space Phys. (ISSN: 0367-8393), 41 488-500.

Case Jonathan L, Crosson William L, Kumar Sujay V, Lapenta William M and Peters-Lidard Christa D 2008 Impacts of high-resolution land surface initialization on regional sensible weather forecasts from the WRF Model; J. Hydrometeor. 9 1249-1266.

Charney J G and Shukla J 1981 Predictability of monsoons; In: Monsoon Dynamics (eds) Lighthill J and Pearce R P, Cambridge University Press, pp. 99-109.

Chen and Dudhia J 2001 Coupling an advanced land surface hydrology model with the Penn State-NCAR MM5 
modeling system. Part I: Model implementation and sensitivity; Mon. Wea. Rev. 129 569-585.

Douville 2002 Influence of soil moisture on the Asian and African monsoons. Part II: Interannual variability; J. Climate 15 701-720, doi: 10.1175/1520-0442(2002) $015<0701:$ IOSMOT $>2.0 . \mathrm{CO} ; 2$.

Fennessy M and Shukla J 1999 Impact of initial soil wetness on seasonal atmospheric prediction; J. Climate 12 3167-3180, doi: 10.1175/15200442(1999)012<3167: IOISWO $>2.0 . \mathrm{CO} ; 2$.

Ferranti L, Slingo J M, Palmer T N and Hoskins B J 1999 The effect of land-surface feedbacks on the monsoon circulation; Quart. J. Roy. Meteor. Soc. 125 1527-1550.

Guo Z, Dirmeyer P A and DelSole T 2011 Land surface impacts on subseasonal and seasonal predictability; Geophys. Res. Lett. 38 L24812. doi: 10.1029/2011 GL049945.

Hong S-Y and Dudhia J 2003 Testing of a new nonlocal boundary layer vertical diffusion scheme in numerical weather prediction applications; 20th Conference on Weather Analysis and Forecasting/16th Conference on Numerical Weather Prediction, Seattle, WA.

Hurk Bart van den et al. 2012 Soil moisture effects on seasonal temperature and precipitation forecast scores in Europe; Clim. Dyn. 38 349-362, doi: 10.1007/s00382-010-0956-2v.

Hauffman G, Adler R, Bolvin D, Gu G, Nelkin E, Bowman K, Hong Y, Stocker E and Wolff D 2007 The TRMM multisatellite precipitation analysis, TCMA: Quasiglobal, multiyear, combined sensor precipitation estimates at fine scales; J. Hydrometeorol. 8 38-55, doi: 10.1175/JHM560.1.

Janjic Z I 2000 Comments on development and evaluation of a convection scheme for use in climate models; J. Atmos. Sci. 573686.

Koster R D and Suarez M J 2003 Impact of land surface initialization on seasonal precipitation and temperature prediction; J. Hydrometeor. 4 408-423.

Koster R D et al. 2004 Regions of strong coupling between soil moisture and precipitation; Science 305 11381140 .

Koster R D, Mahanama S P P, Yamada T J, Gianpaolo Balsamo, Berg A A, Boisserie M, Dirmeyer P A, DoblasReyes F J, Drewitt G, Gordon C T, Guo Z, Jeong J-H, Lawrence D M, Lee W-S, Li Z, Luo L, Malyshev S, Merryfield W J, Seneviratne S I, Stanelle T, van den Hurk B J J M, Vitart F and Wood E F 2010 Contribution of land surface initialization to subseasonal forecast skill:
First results from a multi-model experiment; Geophys. Res. Lett. 37 L02402, doi: 10.1029/2009GL041677.

Koster R D et al. 2011 The second phase of the global landatmosphere coupling experiment: Soil moisture contributions to subseasonal forecast skill; J. Hydrometeor. 12 $805-822$.

Lin Y L, Farley R D and Orville H D 1983 Bulk parameterization of the snow field in a cloud model; J. Clim. Appl. Meteorol. 22 1065-1092.

Monin A S and Obukhov A M 1954 Basic laws of turbulent mixing in the surface layer of the atmosphere (in Russian); Contrib. Geophys. Inst. Acad. Sci. USSR 151 163-187.

Paolino Daniel A, James L Kinter, Ben P Kirtman, Dughong Min and David M Straus 2012 The impact of land surface and atmospheric initialization on seasonal forecasts with CCSM; J. Climate 25 1007-1021, doi: 10.1175/2011JCLI3934.1.

Rajeevan M, Gadgil Sulochana and Bhate Jyoti 2010 Active and break spells of the Indian summer monsoon; Proc. Indian Acad. Sci. (Earth Planet. Sci.) 119(3) 229-247.

Rienecker et al. 2011 MERRA: NASA's modern era retrospective analysis for research and analysis; J. Climate $\mathbf{2 4}$ 3624-3648.

Saha S K, Halder S, Kumar K K and Goswami B N 2011 Pre-onset land surface processes and 'internal' interannual variabilities of the Indian summer monsoon; Clim. Dyn. 36 2077-2089.

Saha S K, Halder S, Rao A S and Goswami B N 2012 Modulation of ISOs by land atmosphere feedback and contribution to the interannual variability of Indian summer monsoon; J. Geophy. Res. 117 D13101, doi: 10.1029/2011JD017291.

Shukla J 1981 Dynamical predictability of monthly means; J. Atmos. Sci. 38 2547-2572.

Unnikrishnan C K, Rajeevan M, Vijaya Bhaskara Rao S and Manoj Kumar 2013 Development of a high resolution land surface dataset for the south Asian monsoon region; Curr. Sci. 105(9) 1235-1246.

Unnikrishnan C K, Rajeevan M and Vijaya Bhaskara Rao S 2015 A study on the role of land-atmosphere coupling on the south Asian monsoon climate variability using a regional climate model; Theoret. Appl. Climatol., doi: 10.1007/s00704-015-1680-y.

Walker J and Rowntree P R 1977 The effect of soil moisture on circulation and rainfall in a tropical model; Quart. J. Roy. Meteorol. Soc. 103 29-46, doi: 10.1002/qj.49710343503. 